\title{
The role of vessel wall physiology in predicting coronary bypass graft patency Steve K Singh ${ }^{1,2}$ and Stephen E Fremes*1,2
}

Address: ${ }^{1}$ Division of Cardiac and Vascular Surgery, Sunnybrook and Women's Health Sciences Centre, 2075 Bayview Avenue, Suite H-410, Toronto, Ontario, M4N 3M5, Canada and ${ }^{2}$ University of Toronto, Toronto, Canada

Email: Steve K Singh - steve.singh@utoronto.ca; Stephen E Fremes* - stephen.fremes@sw.ca

* Corresponding author

Published: 03 March 2006

Journal of Cardiothoracic Surgery2006, I:5 doi:10.1 I86/I749-8090-I-5

This article is available from: http://www.cardiothoracicsurgery.org/content///I/5

(c) 2006Singh and Fremes; licensee BioMed Central Ltd.

This is an Open Access article distributed under the terms of the Creative Commons Attribution License (http://creativecommons.org/licenses/by/2.0), which permits unrestricted use, distribution, and reproduction in any medium, provided the original work is properly cited.

\section{Abstract}

\section{Not applicable.}

\section{Text}

The phase one results from the randomized Radial artery versus Saphenous Vein Patency (RSVP) trial are published in the current issue of the Journal [1]. Fifty-two patients had quantitative angiography with Thrombolysis in Myocardial Infarction (TIMI) flow assessment, approximately 3 months after coronary bypass graft surgery. A subset of 7 patients had in-vivo assessment of graft flow and vessel wall physiology, using intravascular Doppler ultrasound and pharmacologic manipulation. The investigators found that $11 \%$ of radial artery (RA) grafts had either a greater than $50 \%$ stenosis or diffuse narrowing (string sign), no RA was completely occluded, $5 \%$ of long-saphenous veins (LSV) were completely occluded, and the remaining RA or LSV grafts were perfectly patent. RA grafts were found to have intact endothelial function at 3 months post-operatively, whereas LSV grafts did not. Although flow volumes were similar in both conduits, the size match of conduit-to-target vessel was better with RA grafts. Hence, the investigators concluded that the RA is a more physiologic conduit for coronary bypass surgery.

The natural history of coronary bypass grafts suggests that biologic properties of the conduit vessel strongly influence graft function and patency, and the intact physiology of the endothelium is deemed to be a primary determinant [2-4]. The article in the Journal by Chong et al corrob-
Received: 2I February 2006

Accepted: 03 March 2006 
However, maintaining vessel wall physiology may also lead to maladaptive results. The proclivity of arterial conduits to spasm is an example of sensitivity to endogenous and exogenous vasoconstrictors. A sub-group analysis of RA patients from the Radial Artery Patency Study (RAPS) found that use of peri-operative vasoconstrictors (alpha adrenergic agonists) was an independent predictor of RA string sign [5,7]. Calcium channel blockers are often employed post-operatively as an anti-spasmodic therapy. However, their efficacy and the duration of treatment remain controversial [8].

Chong et al also showed that flow volumes were the same in both RA and LSV grafts [1]. This emphasizes the influence of competitive flow on graft patency. Specifically, it has been shown that target vessel stenosis less than $90 \%$ was an independent predictor of RA graft failure (string sign) [7]. This sensitivity, again is a consequence of a functional vessel wall responding to poor flow conditions.

There are certainly advantages and disadvantages to the RA in having preserved vessel wall physiology. There is evidence that string signs (in both RA and IMAs) are transient and do reverse, when studied using serial angiographic imaging [9]. Nonetheless, the most relevant outcome is post-operative patient clinical status. This does not seem to be impacted; no difference in myocardial infarction or angina at 3 months and 12 months has been reported in patients who developed a string sign versus those who did not [10]. Angina occurred in a small group of patients and was related to TIMI 1 flow. The majority of patients with string signs still had greater than TIMI 2 flow and were asymptomatic.

With appropriate harvesting, target vessel selection and peri-operative medical management, the radial artery provides a more physiologically appropriate conduit with functionally normal vessel wall behaviors, when compared to a saphenous vein. The string sign may in many cases be an adaptive consequence of RAs and without clinical consequences. There seem to be no pathological evidence in RAs that show string sign, nor does it seem to be a permanent or clinically significant phenomenon. Using similar measures as Chong et al, Possati et al have shown that endothelial function remains preserved in the RA at 10 -years post-operation [11]. What remains to be seen is if normal vessel physiology will result in improved longterm graft patency by avoiding the process of accelerated atherosclerosis, which is prevalent in venous graft and often occurs secondary to endothelial damage or dysfunction.

\section{Competing interests}

The author(s) declare that they have no competing interests.

\section{Authors' contributions}

SKS and SEF were both equally involved in the conceptualization, research, writing and manuscript preparation of this editorial.

\section{References}

I. Chong WCF, Collins P, Webb CM, DeSouza AC, Pepper JR, Hayward CS, Moat NE: Comparison of flow characteristics and vascular reactivity of radial artery and long saphenous vein grafts. Journal of Cardiothoracic Surgery 2006, I:4.

2. Luscher TF, Tanner FC, Tschudi MR, Noll G: Endothelial dysfunction in coronary artery disease. Annual Review of Medicine 1993, 44:395-4I8.

3. Luscher TF: Vascular biology of coronary artery bypass grafts. Current Opinion in Cardiology 1991, 6:868-76.

4. Goldman S, Copeland J, Moritz T, et al.: Starting aspirin therapy after operation. Effects on early graft patency. In Circulation Volume 84. Issue 2 Department of Veterans Affairs Cooperative Study Group; 1991:520-526.

5. Desai ND, Cohen EA, Naylor CD, Fremes SE, for the RAPS Investigators: A randomized comparison of radial-artery and saphenous-vein coronary bypass grafts. New England Journal of Medicine 2004, 35 I:2303-9.

6. Bach RG, Kern MJ, Donohue TJ, Aguirre FV, Caracciolo EA: Comparison of phasic blood flow velocity characteristics of arterial and venous coronary artery bypass conduits. Circulation 1993, 88:III 33-40.

7. Miwa S, Desai ND, Koyama T, Chan E, Cohen EA, Fremes SE: Radial artery angiographic string sign: clinical consequences and the role of pharmacologic therapy. Annals of Thoracic Surgery 2006, 81 : II2-9.

8. Gaudino M, Glieca F, Luciana N, Alessandrini F, Possati G: Clinical and angiographic effects of chronic calcium channel blocker therapy continued beyond first post-operative year in patients with radial artery grafts. Circulation 200I, I04:164-7.

9. Merlo M, Terzi A, Tespili M, Ferrazzi P: Reversal of radial artery 'string sign' at 6 months follow-up. European Journal of Cardiothoracic Surgery 2003, 23:432-4.

10. Verma S, Szmitko P, Weisel RD, et al.: Should radial artery grafts be routinely used for coronary bypass graft surgery? Circulation 2004, 1 00:e40-e46.

II. Possati G, Gaudino M, Prati F, et al.: Long-term results of radial artery use for myocardial revascularization. Circulation 2003, I08: 1350-4.

\footnotetext{
Publish with Bio Med Central and every
scientist can read your work free of charge
"BioMed Central will be the most significant development for
disseminating the results of biomedical research in our lifetime."
Sir Paul Nurse, Cancer Research UK
Your research papers will be:
- available free of charge to the entire biomedical community
- peer reviewed and published immediately upon acceptance
- cited in PubMed and archived on PubMed Central
• yours - you keep the copyright
Submit your manuscript here:
http://www.biomedcentral.com/info/publishing_adv.asp
} 